\title{
Comparison between Carbon Dioxide and Air Insufflation in Colonoscopy: A Systematic Review and Meta-Analysis Based On Randomized Control Trials
}

\author{
Nádia Korkischko, Wanderley Marques Bernardo, Marina Lordello Passos, Priscilla \\ Cavalheiro Bonifácio, Mileine Valente de Matos, Diogo Turiani Hourneaux de Moura, Martin \\ Coronel*, Edson Ide, Nelson Tomio Miyajima, Paulo Sakai and Eduardo Guimarães Hourneaux \\ de Moura \\ Gastrointestinal Endoscopy Unit, Department of Gastroenterology, Hospital das Clínicas da Faculdade de Medicina \\ da Universidade de São Paulo, São Paulo 05403-000, Brazil
}

Received: February 7, 2017; Accepted: May 3, 2017; Published: May 15, 2017

*Corresponding author: Martin Coronel, Gastrointestinal Endoscopy Unit, Department of Gastroenterology, Hospital das Clínicas da Faculdade de Medicina da Universidade de São Paulo, São Paulo 05403-000, Brazil, Tel: +551198999-7416; Fax: +55112661-6467; Email: martincoronel0@gmail.com

\begin{abstract}
Objectives: The colorectal cancer is a common and lethal neoplasia. Colonoscopy detects diseases in the initial stages decreasing the mortality. Pain and abdominal discomfort are usual complaints associated mainly with the use of air insufflation. Carbon dioxide (CO2) is increasingly utilized to augment tolerance and disposition to repeat the examination. Compare which insufflation method is related to less unpleasant symptoms, safer examination and best performance are objectives of the study.
\end{abstract}

Methods: Electronic databases were accessed selecting only randomized controlled trials comparing insufflation with $\mathrm{CO} 2$ and ambient air in colonoscopy. The evaluated outcomes were pain, abdominal distension and flatulence, cecal intubation rate, cecal intubation and total procedure time, volume of gas, $\mathrm{CO} 2$ measurement, and need of sedation or analgesia, and polyp detection rate.

Results: Thirty randomized controlled trials were selected (4854 patients). Meta-analysis showed reduction in pain risk in the $\mathrm{CO} 2$ group immediately after the colonoscopy (Risk difference-RD 0.11[0.03, $0.19]), 1 \mathrm{~h}(\mathrm{RD} 0.29[0.24,0.34]), 3 \mathrm{~h}$ (RD $0.22[0.11,0.34])$ and $6 \mathrm{~h}$ (RD $0.21[0.17,0.26])$ after colonoscopy. The reduction of flatulence risk $1 \mathrm{~h}$ and $6 \mathrm{~h}$ after the procedure was greater in $\mathrm{CO} 2$ group (RD 0.54 $[0.43,0.66]$ and RD $0.65[0.38,0.92]$, respectively). There were no significant differences between the two groups regarding pain during the procedure, pain and flatulence $24 \mathrm{~h}$ after colonoscopy, abdominal bloating, request for medication, safety, gas volume, polyp detection rate, cecal intubation rate, time to cecum and total procedure time.

Conclusions: $\mathrm{CO} 2$ insufflation improves tolerance to colonoscopy, reducing pain and flatulence out to 6 hours following the procedure.

Keywords: Air; Carbon dioxide; Colonoscopy; Insufflations; Pain

\section{Introduction}

The colorectal cancer (CRC) is the third most common neoplasia around the world, occupying the fourth position in mortality, with an incidence of 1,360,602 new cases and 693,933 deaths in 2012 according to the World Health Organization (WHO) - Globocan database [1]. Colonoscopy is one of the methods indicated for screening of CRC with the objective of detecting the disease in the initial stages, decreasing the mortality $[2,3]$.

However, because of the necessity of gas insufflation for the adequate visualization of the colonic mucosa, patients usually complain about pain and abdominal discomfort during and after the procedure associated mainly with the use of ambient air, which stays in the intestine for a longer period [4] due to the presence of nitrogen gas. To increase the tolerance and the disposition to repeat the examination, the insufflation of carbon dioxide ( $\mathrm{CO} 2)$ is increasingly utilized. $\mathrm{CO} 2$ is rapidly absorbed by the intestinal mucosa and subsequently eliminated by breath, which may lead to less pain, flatulence and distension related to the procedure [5-8]. Comparative analyses between the use of $\mathrm{CO} 2$ and ambient air in colonoscopy were shown in two meta-analyses published previously $[9,10]$.

The objective of this systematic review and metaanalysis is to update this knowledge through new studies comparing which insufflation method is related to less unpleasant symptoms, faster and safer examinations, and to add outcomes that were not yet described in the literature.

\section{Materials and Methods}

\section{Literature search}

Randomized controlled trials (RCTs) that reported the use of $\mathrm{CO} 2$ versus ambient air in colonoscopy published until April 2016 were accessed through the following electronic databases: MEDLINE, SCOPUS, EMBASE, LILACS and CENTRAL (BVS), Cochrane Library, CAPES (Brazil) published theses, in addition to access of bibliographic references ("grey literature") to identify additional articles. Considering the MEDLINE database, the used search strategy was: "Carbon dioxide AND (endoscop* OR 
colonoscop* OR enteroscop*) AND random*". For the additional databases, we employed the terms: "carbon dioxide", "CO2" and "colonoscopy".

\section{Study Selection}

For the study selection, there was no restriction of language, year of publication, patient follow-up time or publication status. After searching the titles and abstracts of the articles selected in the initial search, they were further sorted according the following criteria:

1- Study design: RCT.

2- Population: patients subjected to colonoscopy.

3- Intervention: intestinal insufflation with $\mathrm{CO} 2$.

4- Comparison: intestinal insufflation with ambient air.

5- Outcomes: the evaluated outcomes were pain, abdominal distension and flatulence related to colonoscopy, cecal intubation rate, cecal intubation time and total procedure time, volume of gas used, $\mathrm{CO} 2$ measurement at the end of the procedure, need of sedation or analgesia, and polyp detection rate.

\section{Data Extraction}

The data were extracted from the studies by two independent reviewers. In the case of opinion divergence during the process of data extraction and analysis, the doubts were taken to a discussion group in scientific methodology, obtaining a common agreement.

\section{Risk of bias}

Some data were used to generate the score of each study according to the JADAD score, which is a tool that qualifies the randomized controlled trial according to the description of randomization, blinding and existence of losses during the trial [11]. The prognostic differences between the comparison groups were also evaluated and whether the results of each study were assessed adequately and with sufficient follow-up time.

\section{Statistical analyses}

The software RevMan 5 (Review Manager Version 5.3.5 - Cochrane Collaboration, Copyright (C) 2014) was used to perform the meta-analysis of the outcomes [12]. The difference between results was calculated as the risk difference for dichotomous variables with the Cochran-Mantel-Haenszel (CMH) statistical method with $95 \%$ confidence interval, and as mean difference for continuous variables, using fixed effect and inverse variance as statistical method with $95 \%$ confidence interval. The heterogeneity (I2) between the studies was evaluated and modified whenever possible if $>50 \%$, conducting a sensitivity analysis when an outlier was identified through a funnel plot. When the sensitivity analysis did not bring any impact in the heterogeneity reduction, the analysis was not described and we opted for the random effect. Forest and funnel plots were used for graphical expression of the results.

\section{Results}

Through the initial search strategy, 1,830 trials were identified and we selected 150 of them to completely evaluate their titles and abstracts. Then 120 studies were excluded by the reasons (Figure 1), which resulted in the selection of 30 RCT that were in accordance with the eligibility criteria, with a total of 4,854 patients: 2,469 in the CO2 insufflation group and 2,385 in the ambient air insufflation group. The main characteristics of the selected trials and the individual risk of bias are shown in table 1.

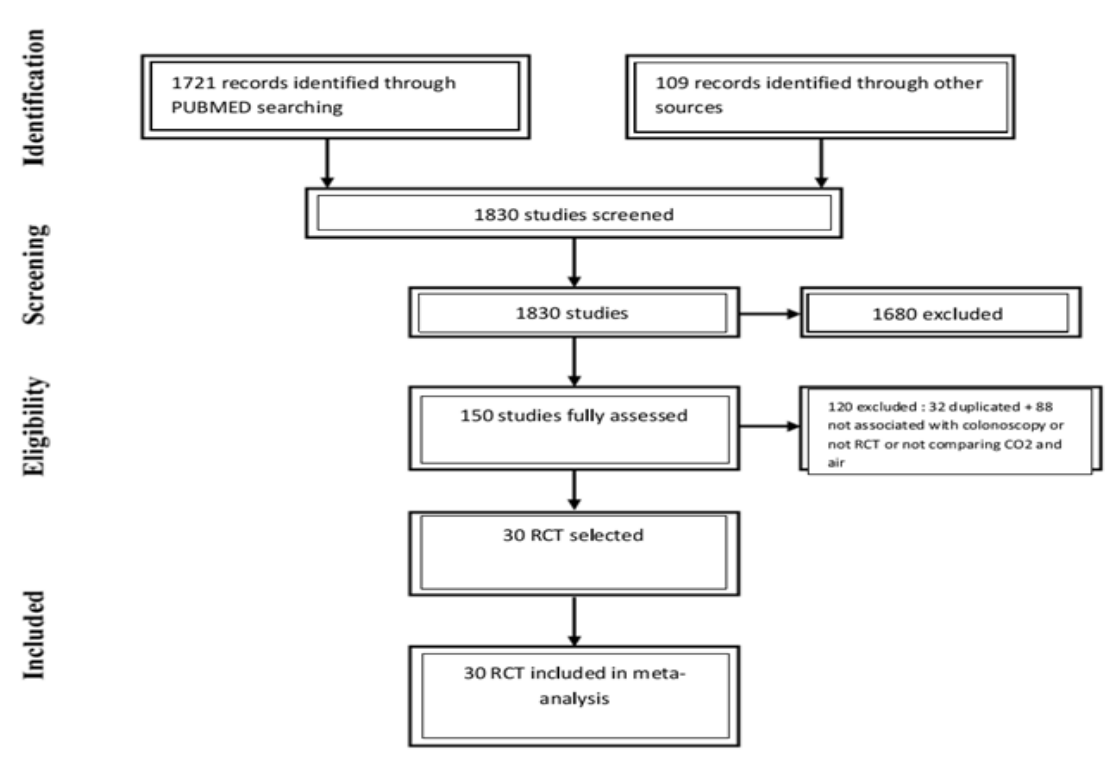

Figure 1: PRISMA flowchart: flow of information through the systematic review 


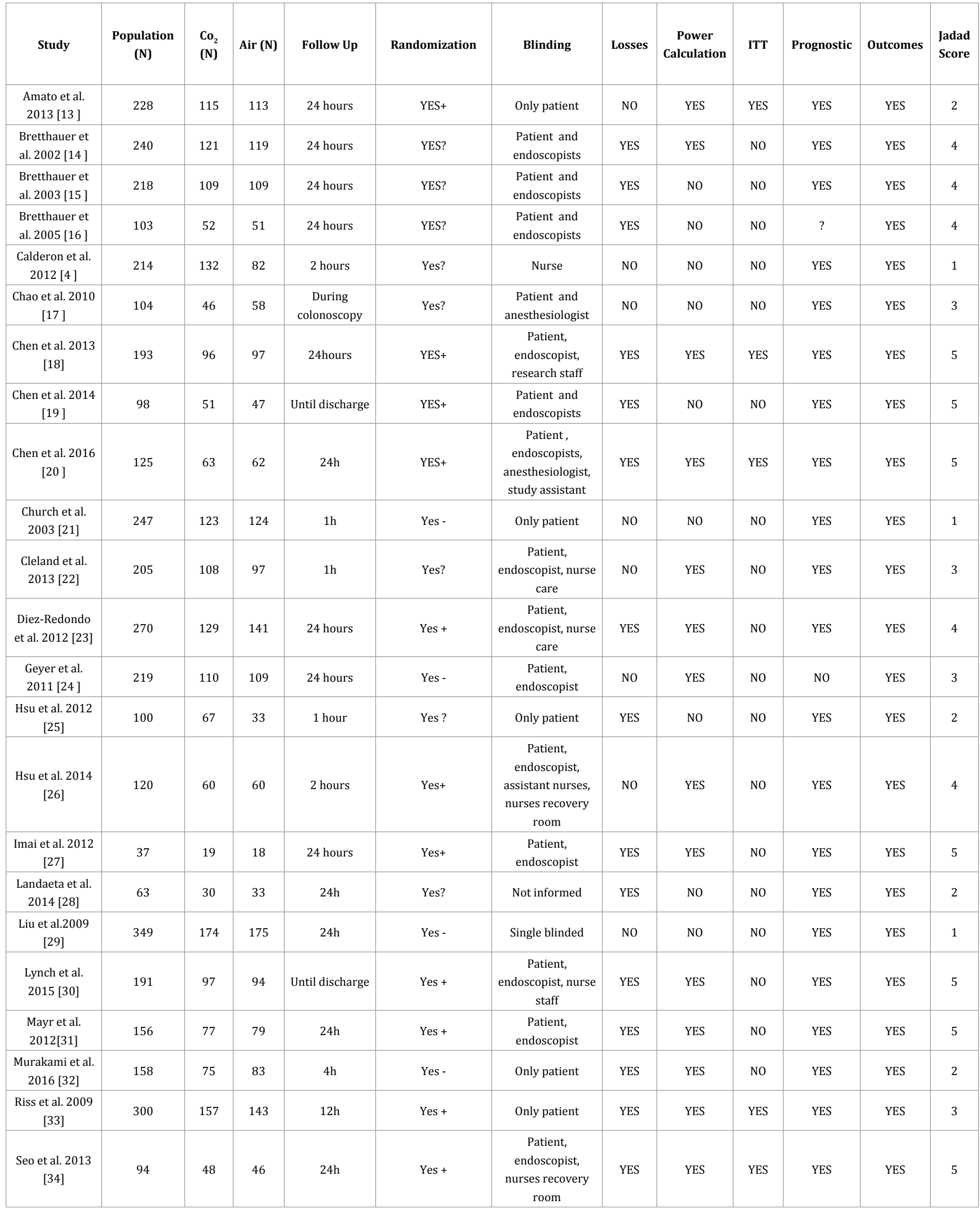




\begin{tabular}{|c|c|c|c|c|c|c|c|c|c|c|c|c|}
\hline $\begin{array}{l}\text { Singh et al. } \\
2012 \text { [35] }\end{array}$ & 142 & 70 & 72 & $\begin{array}{c}\text { Until } \\
\text { discharge }(\sim 3)\end{array}$ & Yes? & $\begin{array}{c}\text { Patient, } \\
\text { endoscopist, nurse }\end{array}$ & NO & NO & NO & NO & YES & 3 \\
\hline $\begin{array}{c}\text { Stevenson et al. } \\
1992[36]\end{array}$ & 56 & 27 & 29 & $24 \mathrm{~h}$ & Yes + & $\begin{array}{l}\text { Patient, } \\
\text { endoscopist }\end{array}$ & NO & NO & NO & $?$ & YES & 4 \\
\hline $\begin{array}{c}\text { Sumanac et al. } \\
2002[37]\end{array}$ & 97 & 46 & 51 & $24 \mathrm{~h}$ & Yes + & $\begin{array}{l}\text { Patient, } \\
\text { endoscopist }\end{array}$ & YES & NO & YES & YES & YES & 5 \\
\hline $\begin{array}{c}\text { Szura et } \\
\text { al.2015[38] }\end{array}$ & 200 & 100 & 100 & $1 \mathrm{~h}$ & Yes + & Only patient & YES & YES & YES & YES & YES & 3 \\
\hline $\begin{array}{c}\text { Uraoka et al. } \\
2009 \text { [39] }\end{array}$ & 114 & 57 & 57 & $6 \mathrm{~h}$ & Yes + & $\begin{array}{l}\text { Patient, } \\
\text { endoscopist }\end{array}$ & YES & YES & YES & YES & YES & 5 \\
\hline $\begin{array}{l}\text { Wong et al. } \\
2008 \text { [40] }\end{array}$ & 93 & 44 & 49 & $2 \mathrm{~h}$ & Yes? & $\begin{array}{c}\text { Patient, } \\
\text { endoscopist, } \\
\text { assessor }\end{array}$ & YES & YES & NO & YES & YES & 4 \\
\hline $\begin{array}{l}\text { Yamano et al. } \\
2010[41]\end{array}$ & 120 & 66 & 54 & $24 \mathrm{~h}$ & Yes? & $\begin{array}{c}\text { Patient, } \\
\text { endoscopist }\end{array}$ & YES & NO & NO & YES & YES & 4 \\
\hline
\end{tabular}

Table 1: General characteristics of studies and individual risks of bias (Randomization: + adequated/ - inadequaded/ ? not informed; Losses: YES: losses described/ NO: losses not described ; ITT: intention to treat analysis; Prognostic: YES: similar baseline characteristics between groups/ NO: different baseline characteristics between groups/ ?: comparative analysis absent ; Outcomes: YES: adequately measured/ NO: not adequately measured)

The Jadad score was used for the critical evaluation of the methodological quality of the trials included in this systematic review with meta-analysis, obtaining $23(77 \%)$ trials with values greater than or equal to three, which means low risk of bias. In relation to the description of losses, there was no need to exclude any trial, because all described values were lower than $20 \%$. There was sample power calculation in $17(57 \%)$ trials and the intention-to-treat analysis was conducted in seven (27\%). The basic characteristics between the groups compared in each trial were similar in $26(87 \%)$ studies and all used adequate tools to measure the outcomes (Table 1). The indications for colonoscopy were similar between the trials (screening, surveillance and diagnostic). There was no uniformity between the trials in relation to the type of colonic preparation used; types and dosages of sedatives/analgesics during the examination; $\mathrm{CO} 2$ insufflation system; patient follow-up time and number of colonoscopists involved in each trial.

\section{Abdominal pain}

Twenty-eight randomized controlled trials (RCTs) evaluated the pain related to colonoscopy [4,13,14,16,18-41]. However, the present meta-analysis included only trials with complete data and the same score of pain measurement. Whenever the continuous variable analysis (pain score mean/median) was not possible, the data were meta-analyzed using dichotomous variables (pain VS zero pain). The pain was evaluated during and immediately after the colonoscopy, as well as $1 \mathrm{~h}, 3 \mathrm{~h}, 6 \mathrm{~h}$ and $24 \mathrm{~h}$ after the procedure.

\section{Pain during colonoscopy}

During the procedure, there was statistical difference considering absence of pain favoring the $\mathrm{CO} 2$ insufflation group (RD $0.10[0.03,0.16] ; \mathrm{I} 2=55 \%$ ). However, if we exclude the trial by Wong et al. [40] from this analysis in order to reduce the heterogeneity related to the publication bias, the difference between groups loses statistical significance (RD 0.06 [-0.01, 0.13]; I2=0) [14,16,22,36,40] (Figure 2).

As for the pain score, there is no difference between the groups (MD $-0.15[-2.56,2.25])$, but with heterogeneity of $100 \%$ $[21,22,25,40]$.

\begin{tabular}{|c|c|c|c|c|c|c|c|c|}
\hline Study or Subgroup & $\begin{array}{r}\mathrm{CO} 2 \\
\text { Events }\end{array}$ & & $\begin{array}{r}\text { Air } \\
\text { Events }\end{array}$ & & Weight & $\begin{array}{l}\text { Risk Difference } \\
\text { M.H, Fixed, } 95 \% \mathrm{Cl}\end{array}$ & $\begin{array}{c}\text { Risk Difference } \\
\text { M.H, Fixed, } 95 \% \mathrm{Cl}\end{array}$ & \\
\hline Bretthauer 2002 & 60 & 121 & 48 & 119 & $35.5 \%$ & $0.09[-0.03,0.22]$ & - & \\
\hline Bretthauer 2005 & 5 & 43 & 2 & 42 & $12.6 \%$ & $0.07[-0.05,0.18]$ & 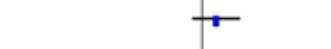 & \\
\hline Cleland 2013 & 34 & 108 & 24 & 96 & $30.0 \%$ & $0.06[-0.06,0.19]$ & - & \\
\hline Stevenson 1992 & 5 & 27 & 8 & 29 & $8.3 \%$ & $-0.09[-0.31,0.13]$ & $\longrightarrow$ & \\
\hline Wong 2008 & 20 & 44 & 7 & 49 & $13.7 \%$ & $0.31[0.13,0.49]$ & $\longrightarrow$ & \\
\hline Total $(95 \% \mathrm{Cl})$ & & 343 & & 335 & $100.0 \%$ & $0.10[0.03,0.16]$ & $\gamma$ & \\
\hline Total events & 124 & & 89 & & & & & \\
\hline $\begin{array}{l}\text { Heterogeneity: } \mathrm{Chi}^{2}=8 \\
\text { Test for overall effect: }\end{array}$ & $\begin{array}{l}3.98, d f= \\
Z=2.82\end{array}$ & $\begin{array}{l}4(P=0 \\
P=0.00\end{array}$ & $0.06) ; 1^{2}=$ & $=55 \%$ & & & $\begin{array}{cccc}-1 & -0.5 & 0 & 0.5 \\
& \text { Favour [Air] Favour [CO2] }\end{array}$ & 1 \\
\hline
\end{tabular}




\section{Pain at the end of colonoscopy}

Immediately after the colonoscopy, there was a reduction in the pain risk in the $\mathrm{CO} 2$ group in comparison with ambient air (RD $0.16[0.09,0.23]$; I2=66\%). The trial by Yamano et al [41] was excluded from this analysis to reduce the heterogeneity (RD $0.11[0.03,0.19] ; \mathrm{I} 2=34 \%$ ), maintaining the difference between the groups $[24,26,28,37,41]$ (Figure 3).

Considering the calculation of the pain score, there was significant statistical difference, meaning that the $\mathrm{CO} 2$ group was associated with lower values of the numerical pain scale. (MD -0.71[-1.39, - 0.02]; $\left.\mathrm{I}^{2}=94 \%\right)[21,24,25,26,38]$.

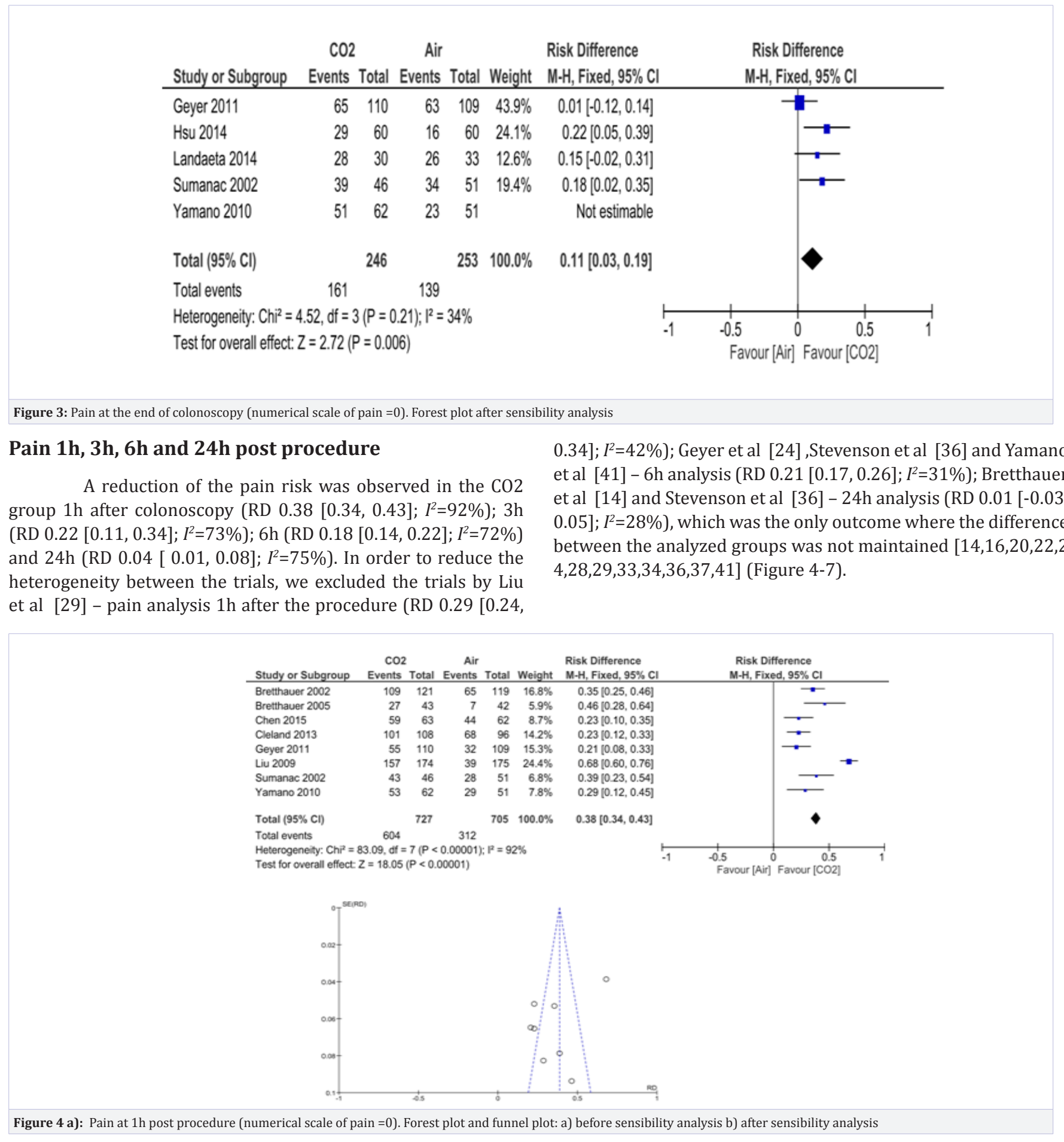

Citation: Martin Coronel, Nádia Korkischko, et.al. (2017) Comparison between Carbon Dioxide and Air Insufflation in Colonoscopy: A Systematic Review and Meta-Analysis Based On Randomized Control Trials. Gastroenterol Pancreatol Liver Disord 4(4):1-11. 


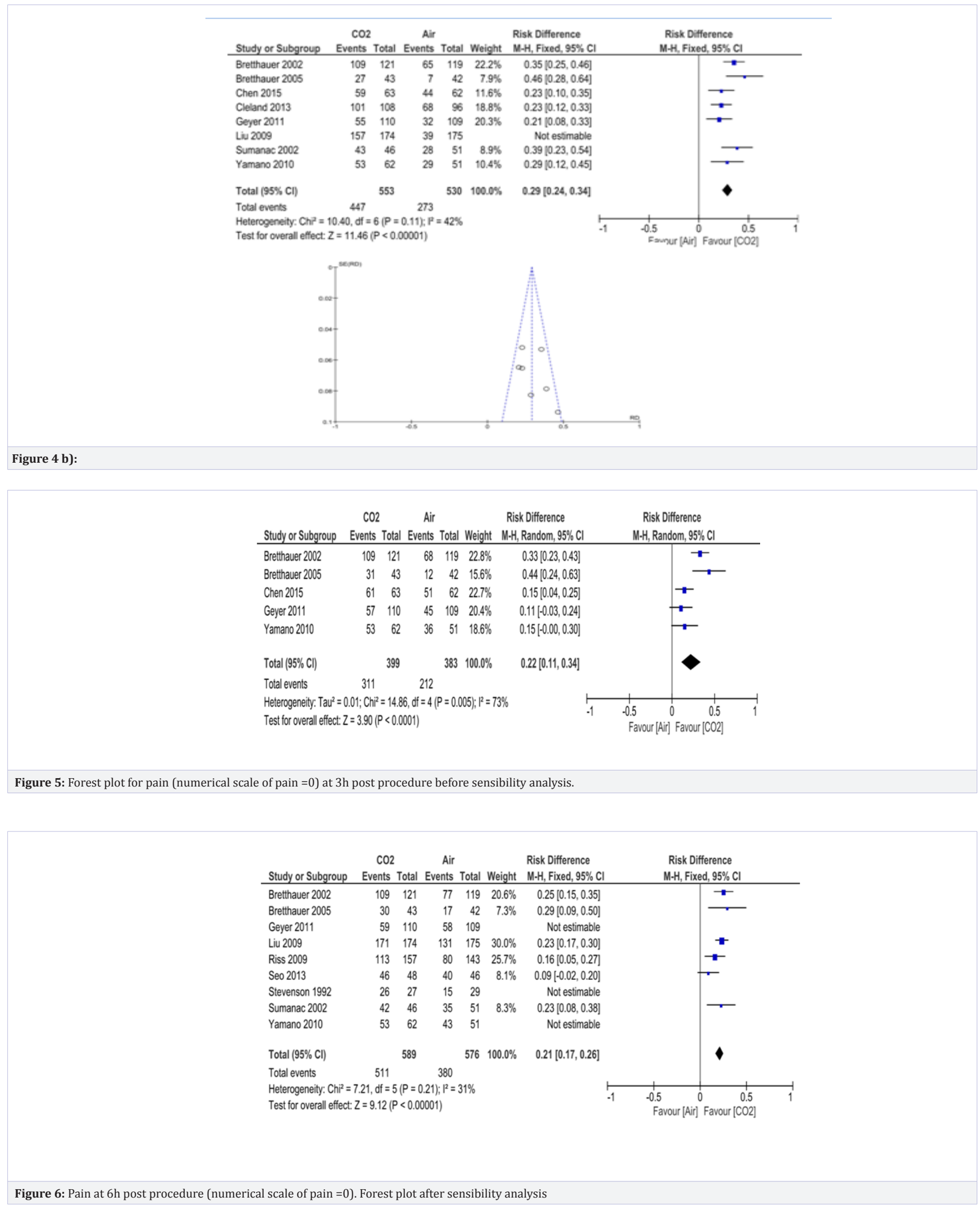

Citation: Martin Coronel, Nádia Korkischko, et.al. (2017) Comparison between Carbon Dioxide and Air Insufflation in Colonoscopy: A 


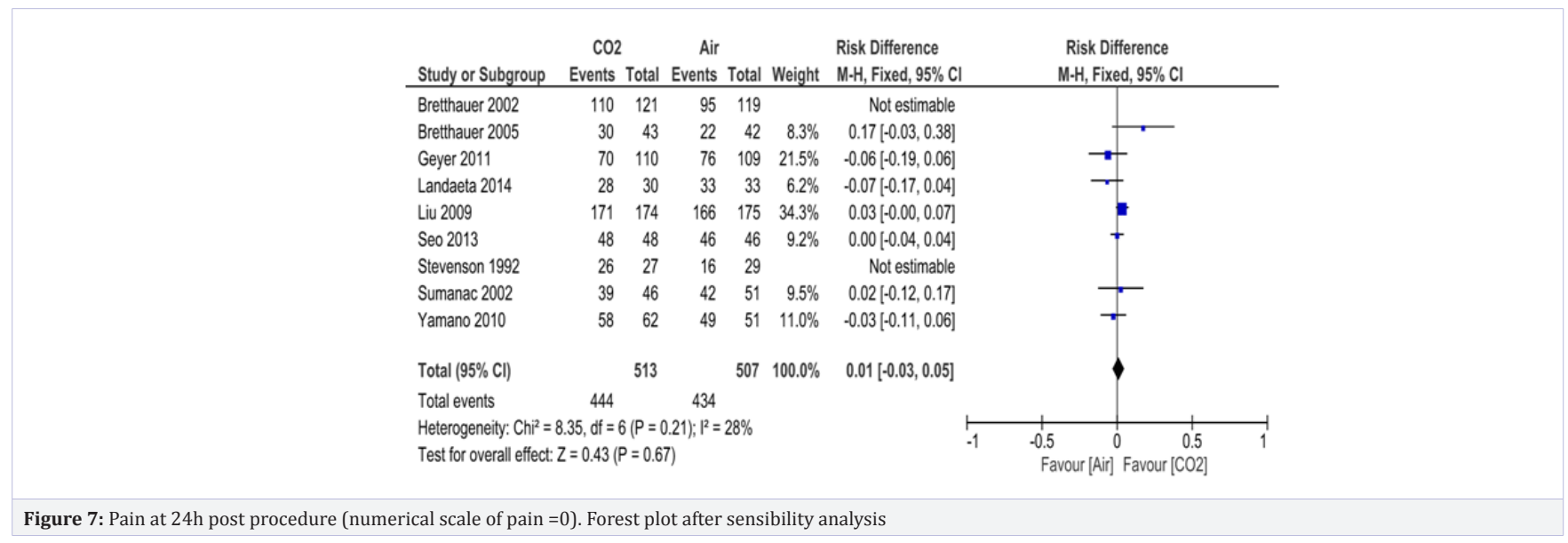

\section{Volume of gas during colonoscopy}

Two trials evaluated the volume of gas used during the colonoscopy, showing that there was no significant statistical difference when the $\mathrm{CO} 2$ insufflation group and the ambient air insufflation group were compared (MD -0.08 [-1.03, 0,86] e $\mathrm{I} 2=44 \%)[15,41]$.

\section{Flatus $1 \mathrm{~h}, 6 \mathrm{~h}$ and $24 \mathrm{~h}$ post procedure}

Two trials evaluated the presence of flatus reported by the patients after the procedure. The reduction of flatulence risk $1 \mathrm{~h}$ and $6 \mathrm{~h}$ after the procedure was greater in the $\mathrm{CO} 2$ group (RD $0.54[0.43,0.66] ; \mathrm{I} 2=36 \%$ ) and (RD 0.65[0.38,0.92]; I2=82\%), respectively. In the analysis of $24 \mathrm{~h}$ after colonoscopy, there was no difference between the groups (RD 0.21[-0.27,0.68]; $\mathrm{I}^{2}=91$ ) $[36,37]$.

\section{Bloating at the end of procedure}

Two trials did not show any difference related to the abdominal bloating score between the compared insufflation groups (MD -1.20 [-3.01, 0.62]; I2=93\%) [24,26].

\section{Request of medication}

There was no difference in relation to the request of medication during the procedure between the $\mathrm{CO} 2$ and ambient air insufflation groups in the two trials included in this outcome (RD - $0.06[-0.13,0] ; \mathrm{I} 2=57 \%$ ) $[13,18]$.

\section{Cecal intubation}

Twelve trials demonstrated that there was no difference in relation to the cecal intubation rate between the $\mathrm{CO} 2$ insufflation group and the ambient air insufflation group (RD $-0.01[-0.02,0.01] ; \mathrm{I} 2=0)[13-15,18,20,21,24,29,35,38,40,41]$ (Figure 8).
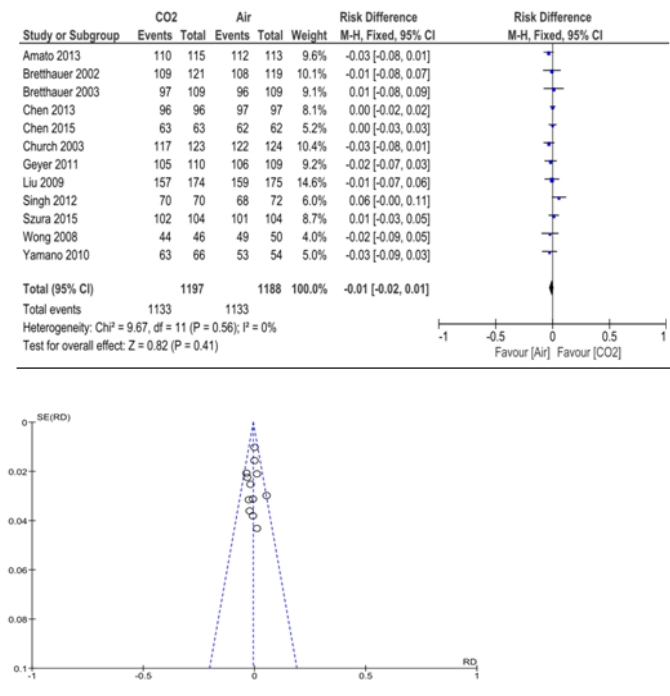

Figure 8: Cecal intubation rate. Forest plot and funnel plot 


\section{Polyp detection rate}

Comparing the $\mathrm{CO} 2$ and ambient air groups, there was no difference in the polyp detection rate during the colonoscopy in the nine trials considered (RD $-0.01[-0.06,0.03] ; \mathrm{I} 2=0)[13,22$ 26,31,38,40] (Figure 9).

\section{Time to cecum and total procedure time}

There was no difference between the groups in relation to the time to reach the cecum (MD $-0.17[-0.44,0.11] ; \mathrm{I} 2=47 \%$ ) and in relation to the total procedure time (MD $0.03[-0.41,0.47])$; $\mathrm{I} 2=21 \%$ ) $[14,15,19,20-22,24-29,31,34,38,41]$ (Figure 10, 11).

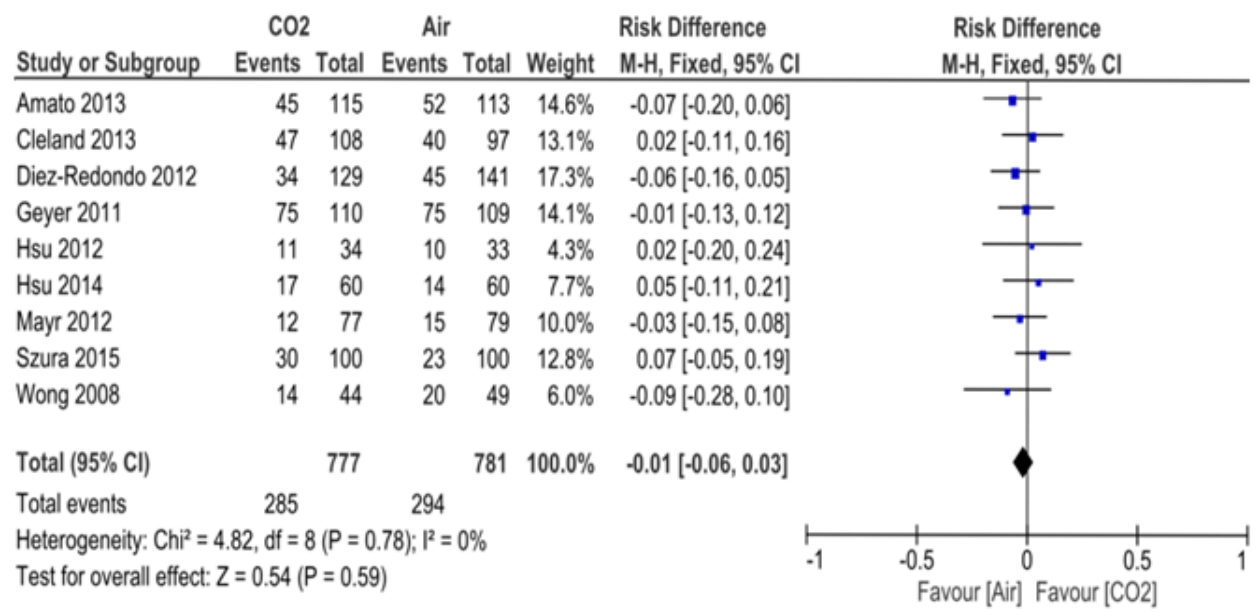

Figure 9: Polyp detection rate Forest plot.

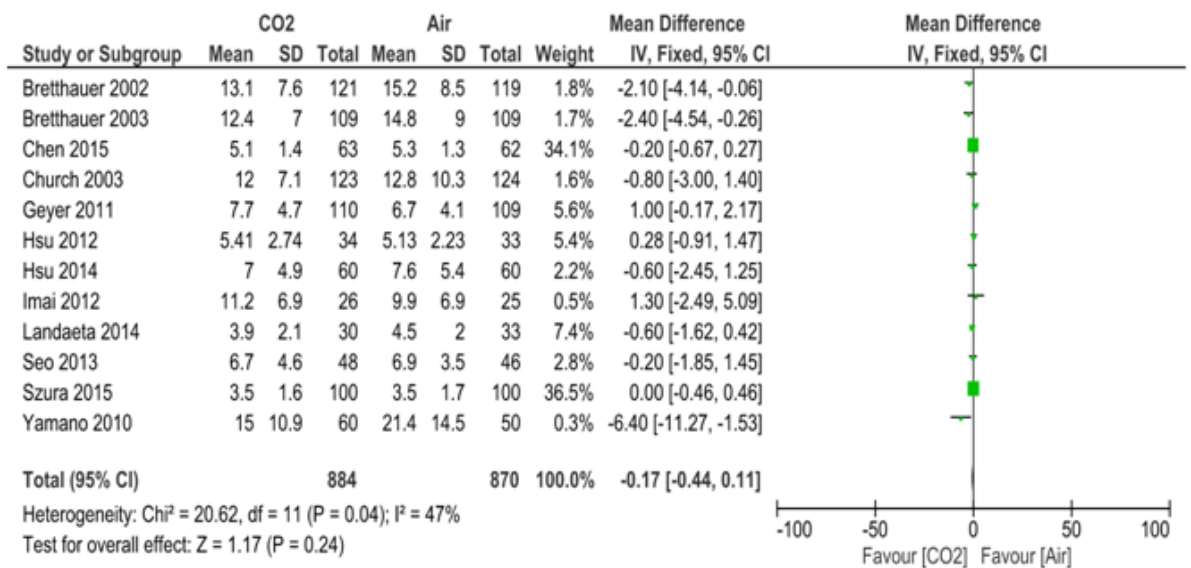

Figure 10 : Time to cecum (minutes). Forest plot

Citation: Martin Coronel, Nádia Korkischko, et.al. (2017) Comparison between Carbon Dioxide and Air Insufflation in Colonoscopy: A 


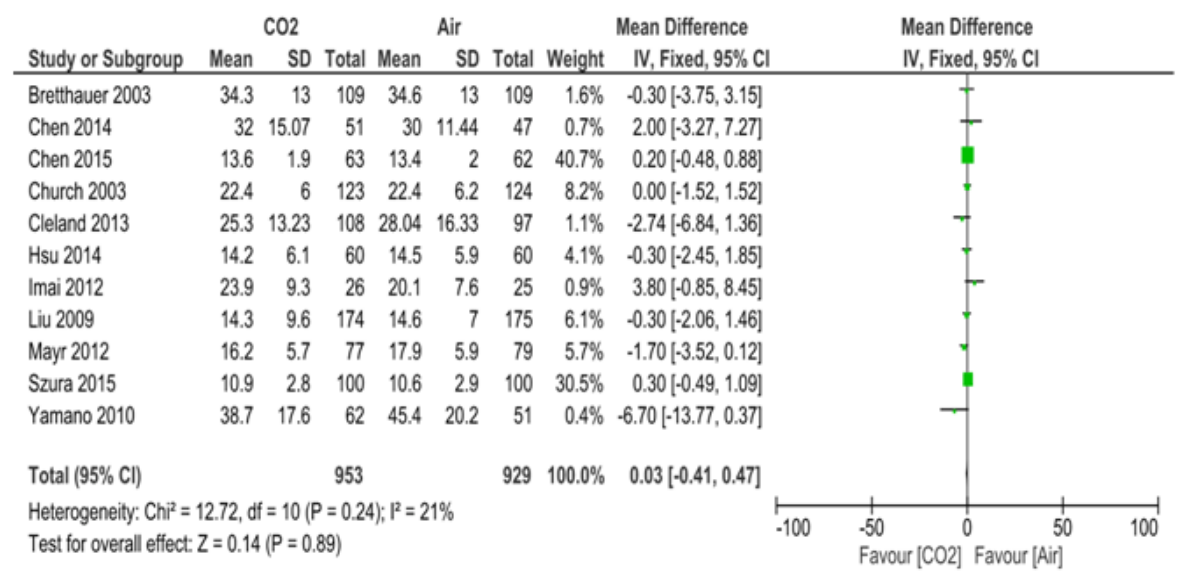

Figure 11 : Total procedure time (minutes). Forest plot

\section{C02 measurements after examination}

The CO2 measurement (mmHg) after the examination was compared between the groups, showing no difference between the two trials included in this outcome (MD $0.23[-2.12$, 2.58]; $I^{2}=86 \%$ ) [24,34]

\section{Discussion}

The CO2 use in endoscopic examinations demonstrated that it is an efficient strategy to allow a faster absorption by the intestinal mucosa, causing less unpleasant symptoms related to the procedure [5-8].

In our systematic review, there was no difference between the $\mathrm{CO} 2$ insufflation group and the ambient air insufflation group in relation to pain reported during the examination. However, two meta-analysis $[9,10]$ showed that the $\mathrm{CO} 2$ was associated to lower pain scores and lower pain risk during the procedure. This difference may be explained because we performed the sensibility analysis in cases of heterogeneity $>50 \%$, splitting the trials between the outcomes "pain during the colonoscopy" and "pain at the end of the colonoscopy", which was not done in the two cited meta-analyses, in addition to the inclusion of new trials.

We demonstrated that the pain risk was lower with the use of $\mathrm{CO} 2$ in the analysis of $1 \mathrm{~h}, 3 \mathrm{~h}$ and $6 \mathrm{~h}$ after the examination; no clear evidence was found between the groups in the outcome of $24 \mathrm{~h}$. Similar results were obtained in the studies cited above, except for the $3 \mathrm{~h}$ analysis, which was not performed.

The $\mathrm{CO} 2$ measurement after the procedure was compared between groups, with no significant statistical difference, which is also shown in the trials included in the systematic review by Wu et al [9]. It should be taken into account that the indirect measurements of $\mathrm{CO} 2$ through transcutaneous or end tidal monitoring may not be reliable. Arterial blood gases are more adequate, but not acceptable by the patients [42]. There was also no difference in relation to cecal intubation. Sajid et al [10] demonstrated that the cecum was reached faster using $\mathrm{CO} 2$, but our meta-analysis did not arrive at the same conclusion.

Among the strong points of our systematic review and meta-analysis, we can cite the addition of trials of high methodological quality ( $77 \%$ with Jadad $>3)$, the number of involved patients and the outcomes that were not evaluated in the previous meta-analysis, such as abdominal distention, polyp detection rate, total procedure time, request for analgesia/ sedation during the examination.

Among the limitations of this study, we should punctuate that the high heterogeneity of some outcomes led to the execution of sensibility analysis, modifying some results, which is not possible especially in the outcomes that involve only two studies. Examinations performed in different periods (1992-2015) with particulate clinical practices, different employed methodologies and various forms of outcome measurements are some of the reasons. The presence of analgesia/sedation, type of preparation performed, exam time related to the endoscopist experience and the volume of gas used may relate more with pain, abdominal distention and flatulence than with the type of gas used during the examination.

The cost of a CO2 insufflator varies between 7,000 and 7,400 Euros. The cost of the CO2 gas per colonoscopy is less than 1 euro [43]. Yamano et al. state that the total cost of one endoscopy increases about $2.5 \%$ with the use of $\mathrm{CO} 2$ [41]. Thus, the costbenefit relationship between these two insufflation methods must be analyzed in other studies, considering the financial reality of dozens of developing countries.

Trials that evaluate the complications related to the 
colonoscopy and the evolution of those patients depending on the type of gas used are very important to consolidate the $\mathrm{CO} 2$ in the clinical practice.

\section{Conclusion}

CO2 insufflation improves tolerance to colonoscopy, reducing pain immediately, and 1, 3 and 6 hours after the procedure. $\mathrm{CO} 2$ is also associated with lower pain scores and reduction of flatulence. However, there was no difference in polyp detection rate, cecal intubation and procedure time between groups.

\section{Acknowledgments}

We thank all the professionals of the Hospital das Clinicas, Endoscopy Unit at the University of São Paulo that worked on this research paper.

\section{Declarations}

\section{Clinical Trial Registration:}

N/A as this is e systematic review.

\section{References}

1. WHO. Globocan 2012: Estimated cancer incidence, mortality and prevalence wordwide in 2012. IARC. 2015

2. Finlay A Macrae, Johanna Bendell. Clinical presentation, diagnosis, and staging of colorectal cancer. UpToDate. 2015.

3. Carroll M, Seaman H, Halloran S. Tests and investigations for colorectal cancer screening. ClinBiochem. 2014;47(10-11):921-939. doi 10.1016/j.clinbiochem.2014.04.019

4. Fernández-Calderón M, Muñoz-Navas MÁ, Carrascosa-Gil J, BetésIbáñez MT, de-la-Riva S, Prieto-de-Frías $C$, et al. Carbon dioxide vs. air insufflation in ileo-colonoscopy and in gastroscopy plus ileo-colonoscopy: a comparative study. Rev EspEnferm Dig. 2012;104(5):237-241.

5. Phaosawasdi K, Cooley W, Wheeler J, Rice P. Carbon dioxide-insufflated colonoscopy: an ignored superior technique. Gastrointest Endosc. 1986;32(5):330-333.

6. Rogers BH. CO2 during colonoscopy for safety and comfort. Gastrointest Endosc. 1985;31(2):108-109.

7. Hussein AM, Bartram CI, Williams CB. Carbon dioxide insufflation for more comfortable colonoscopy. Gastrointest Endosc. 1984;30(2):6870.

8. Dellon ES, Hawk JS, Grimm IS, Shaheen NJ. The use of carbon dioxide for insufflation during GI endoscopy: a systematic review. Gastroint Endosc. 2009;69(4):843-849. doi:10.1016/j.gie.2008.05.067.

9. Wu J, Hu B. The role of carbon dioxide insufflation in colonoscopy: a systematic review and meta-analysis. Endoscopy. 2012;44(2):128136. doi: 10.1055/s-0031-1291487.

10.Sajid MS, Caswell J, Bhatti MI, Sains P, Baig MK, et al. Carbon dioxide insufflation versus conventional air insufflation for colonoscopy: a systematic review and meta-analysis of published randomized controlled trials. Colorectal Dis. 2015;17(2):111-123. doi:10.1111/ codi.12837.

11.Jadad AR, Moore RA, Carroll D, Jenkinson C, Reynolds DJ, et al. Assessing the quality of reports of randomized clinical trials: is blinding necessary? Control Clin Trials. 1996;17(1):1-12.

12. Review Manager (RevMan) [Computer program]. Version 5.3.5. Copenhagen: The Nordic Cochrane Centre, The Cochrane Collaboration. 2014.

13. Amato A, Radaelli F, Paggi S, Baccarin A, Spinzi G, et al. Carbon dioxide insufflation or warm-water infusion versus standard air insufflation for unsedated colonoscopy: a randomized controlled trial. Dis Colon Rectum. 2013;56(4):511-518.doi:10.1097/DCR.0b013e318279addd.

14. Bretthauer M, Thiis-Evensen E, Huppertz-Hauss G, Gisselsson L, Grotmol T et al. NORCCAP (Norwegian colorectal cancer prevention): a randomised trial to assess the safety and efficacy of carbon dioxide versus air insufflation in colonoscopy. Gut. 2002;50(5):604-607.

15. Bretthauer M, Hoff GS, Thiis-Evensen E, Huppertz-Hauss G, Skovlund E. Air and carbon dioxide volumes insufflated during colonoscopy. Gastrointest Endosc. 2003;58(2):203-206.

16. Bretthauer M, Lynge AB,Thiis-Evensen E, Hoff G, Fausa O, Aabakken L. Carbon dioxide insufflation in colonoscopy: safe and effective in sedated patients. Endoscopy. 2005;37(8):706-709.

17. Chao IF, Chiu HM, Liu WC, Liu CC, Wang HP, et al. Significant hypercapnia either in $\mathrm{CO}(2)$-insufflated or air-insufflated colonoscopy under deep sedation. Acta Anaesthesiol Taiwan. 2010;48(4):163-166. doi: 10.1016/j.aat.2010.12.002

18. Chen PJ, Li CH, Huang TY, Yu-Lueng Shih, Heng-Cheng Chu, et al. Carbon dioxide insufflation does not reduce pain scores during colonoscope insertion in unsedated patients: a randomized, controlled trial. Gastrointest Endosc. 2013;77(1):79-89.

19. Chen YJ, Lee J, Puryear M, Wong RK, Lake JM, et al. A randomized controlled study comparing room air with carbon dioxide for abdominal pain, distention, and recovery time in patients undergoing colonoscopy. Gastroenterol Nurs. 2014;37(4):273-278. doi: 10.1097/ SGA.0000000000000054

20. Chen SW, Hui CK, Chang JJ, Lee TS, Chan SC, Chien CH, et al. Carbon dioxide insufflation during colonoscopy can significantly decrease post-interventional abdominal discomfort in deeply sedated patients: A prospective, randomized, double blind, controlled trial. J Gastroenterol Hepatol. J Gastroenterol Hepatol. 2016;31(4):808-813. doi: $10.1111 /$ jgh.13181

21. Church J, Delaney C. Randomized, controlled trial of carbon dioxide insufflation during colonoscopy. Dis Colon Rectum. 2003;46(3):322326.

22. Cleland A, Carryer J, La Grow S. Carbon dioxide insufflation 
during colonoscopy: a randomised controlled trial. N Z Med J. 2013;126(1382):87-94.

23. Díez-Redondo P, Gil-Simón P, Alcaide-Suárez N, Atienza-Sánchez R, Barrio-Andrés J, De-la-Serna-Higuera C, et al. Comparison between insufflation with air or carbon dioxide during the colonoscopy in sedated patients with propofol. Rev Esp Enferm Dig. 2012;104(8):411417.

24. Geyer M, Guller U, Beglinger C. Carbon dioxide insufflation in routine colonoscopy is safe and more comfortable: results of a randomized controlled double-blinded trial. Diagn Ther Endosc. 2011;2011:378906. doi: 10.1155/2011/378906

25. Hsu WH, Sun MS, Lo HW, Tsai CY, Tsai YJ. Carbon dioxide insufflation during withdrawal of the colonoscope improved postprocedure discomfort: a prospective, randomized, controlled trial. Kaohsiung J Med Sci. 2012;28(5):265-269.

26. Hsu WF, Hu WH, Chen YN, Lai HH, Chen MK, Chang LC, et al. Carbon dioxide insufflation can significantly reduce toilet use after colonoscopy: a double-blind randomized controlled trial. Endoscopy. Endoscopy. 2014;46(3):190-195. doi: 10.1055/s-0034-1365016

27. Imai A, Kato M, Ono S, Shimizu Y, Takeda H, Asaka M. Efficacy of carbon dioxide-insufflating colonoscopy inpatients with irritable bowel syndrome: a randomized double-blind study. J Gastroenterol Hepatol. 2012;27(10):1623-1628. doi: 10.1111/j.1440-1746.2012.07208.x

28. Landaeta JL, Dias CM, Paternina RJ, Armas V, Prado Z, Urdaneta C. Experiencia preliminar com insuflacion de dióxido de carbono versus aire en colonoscopia ambulatoria consedación sin monitoreo de anestesiología. Gen. 2014; 68(2).

29. Liu X, Liu D, Li J, Ou D, Zhou Z. Safety and efficacy of carbon dioxide insufflation during colonoscopy. J Cent South Univ(Med Sci). 2009;34(8):825-859.

30. Lynch I, Hayes A, Buffum MD, Conners EE. Insufflation using carbon dioxide versus room air during colonoscopy: comparison of patient comfort, recovery time, and nursing resources. Gastroenterol Nurs. 2015;38(3):211-217. doi: 10.1097/SGA.0000000000000109

31. Mayr M, Miller A, Gauger U, Rosch T. CO2 versus air insufflation for private practice routine colonoscopy: results of a randomized double blind trial. Z Gastroenterol. 2012; 50(5):445-448.

32. Murakami K, Kataoka H, Hayano J, Fukuta H, Mori Y, Nishiwaki H, et al. Autonomic nervous responses in colorectal polypectomy: Randomized control trial comparing air and carbon dioxide insufflation. Dig Endosc. 2016;28(2):203-209.

33. Riss S, Akan B, Mikola B, Rieder E, Karner-Hanusch J, Dirlea D, et al. CO2 insufflation during colonoscopy decreases post-interventional pain in deeply sedated patients: a randomized controlled trial. Wien Klin Wochenschr. 2009;121(13-14):464-468. doi: 10.1007/s00508009-1202-y
34. Seo EH, Kim TO, Park MJ, Kim HJ, Shin BC, Woo JG, et al. The efficacy and safety of carbon dioxide insufflation during colonoscopy with consecutive esophagogastroduodenoscopy in moderately sedated outpatients: a randomized, double-blind, controlled trial. J Clin Gastroenterol. 2013;47(5):e45-9. doi: 10.1097/ MCG.0b013e31825c023a

35. Rajvinder Singh, Eu Nice Neo, Nazree Nordeen, Ganesananthan Shanmuganathan, Angelie Ashby, Sharon Drummond, et al. Carbon dioxide insufflation during colonoscopy in deeply sedated patients. World J Gastroenterol. 2012;18(25):3250-3253. doi: 10.3748/wjg. v18.i25.3250

36. Stevenson GW, Wilson JA, Wilkinson J, Norman G, Good-acre RL. Pain following colonoscopy: elimination with carbon dioxide. Gastrointest Endosc. 1992;38(5):564-567.

37. Sumanac K, Zealley I, Fox BM, Rawlinson J, Salena B, Marshall JK, et al. Minimizing postcolonoscopy abdominal pain by using $\mathrm{CO}(2)$ insufflation: a prospective, randomized, double blind, controlled trial evaluating a new commercially available $\mathrm{CO}(2)$ delivery sys-tem. Gastrointest Endosc. 2002;56(2):190-194.

38. Szura M, Pach R, Matyja A, Kulig J. Carbon dioxide insufflation during screening unsedated colonoscopy: a randomised clinical trial. Eur J Cancer Prev. 2015;24(1):37-43. doi:10.1097/CEJ.0000000000000047

39. Uraoka T, Kato J, Kuriyama M, Hori K, Ishikawa S, Harada K, et al. $\mathrm{CO}(2)$ insufflation for potentially difficult colonoscopies: efficacy when used by less experienced colonoscopists. World J Gastroenterol. 2009;15(41):5186-5192.

40.Wong JC, Yau KK, Cheung HY, Wong DC, Chung CC, Li MK. Towards painless colonoscopy: a randomized controlled trial on carbon dioxide-insufflating colonoscopy. ANZ J Surg. 2008;78(10):871-874. doi: 10.1111/j.1445-2197.2008.04683.x

41. Yamano HO, Yoshikawa K, Kimura T, Yamamoto E, Harada E, Kudou $\mathrm{T}$, et al. Carbon dioxide insufflation for colonoscopy: evaluation of gas volume, abdominal pain, examination time and transcutaneous partial CO2 pressure. J Gastroenterol. 2010 ;45(12):1235-1240. doi: 10.1007/s00535-010-0286-5

42. Lord AC, Riss S. Is the type of insufflation a key issue in gastrointestinal endoscopy? World J Gastroenterol. 2014;20(9):2193-2199. doi: 10.3748/wjg.v20.i9.2193

43. Janssens F, Deviere J, Eisendrath P, Dumonceau JM. Carbon dioxide for gut distension during digestive endoscopy: technique and practice survey. World J Gastroenterol. 2009;15(12):1475-1479. 